\title{
Below-Ground Attack by the Root Knot Nematode Meloidogyne graminicola Predisposes Rice to Blast Disease
}

\author{
Tina Kyndt, ${ }^{1}$ Henok Yimer Zemene, ${ }^{1,4}$ Ashley Haeck, ${ }^{2}$ Richard Singh, ${ }^{1}$ David De Vleesschauwer, ${ }^{4}$ \\ Simon Denil, ${ }^{3}$ Tim De Meyer, ${ }^{3}$ Monica Höfte, ${ }^{4}$ Kristof Demeestere,${ }^{2}$ and Godelieve Gheysen ${ }^{1}$ \\ ${ }^{1}$ Department Molecular Biotechnology, Ghent University, Coupure links 653, B-9000 Ghent, Belgium; ${ }^{2}$ Department of \\ Sustainable Organic Chemistry and Technology, Research Group EnVOC, Ghent University, Coupure links 653, B-9000 Ghent, \\ Belgium; ${ }^{3}$ Department of Mathematical Modelling, Statistics and Bioinformatics, Ghent University; and ${ }^{4}$ Department of Crop \\ Protection, Ghent University
}

Accepted 25 January 2017.

\begin{abstract}
Magnaporthe oryzae (rice blast) and the root-knot nematode Meloidogyne graminicola are causing two of the most important pathogenic diseases jeopardizing rice production. Here, we show that root-knot nematode infestation on rice roots leads to important above-ground changes in plant immunity gene expression, which is correlated with significantly enhanced susceptibility to blast disease. A detailed metabolic analysis of oxidative stress responses and hormonal balances demonstrates that the above-ground tissues have a disturbed oxidative stress level, with accumulation of $\mathrm{H}_{2} \mathrm{O}_{2}$, as well as hormonal disturbances. Moreover, double infection experiments on an oxidative stress mutant and an auxin-deficient rice line indicate that the accumulation of auxin in the above-ground tissue is at least partly responsible for the blast-promoting effect of rootknot nematode infection.
\end{abstract}

Due to their unspecific and generally below-ground symptoms, nematode attacks frequently remain undetected in agricultural crops. Nevertheless, studies estimate that plant-parasitic nematodes are responsible for more than US\$80 billion losses in worldwide agriculture annually (Nicol et al. 2011) and that at least $20 \%$ of these losses are related to rice production (Sasser and Freckman 1987). Rice is one of the major crops in the world, with a global production of more than 738 million tons in 2013 (FAOSTAT 2013). It is particularly produced and consumed in tropical and subtropical regions, with a human consumption exceeding $100 \mathrm{~kg}$ per capita annually in many Asian countries and some African countries (Seck et al. 2012). Recently, a shift from traditional irrigated rice cultivation systems towards aerobic rice production has been promoted in areas where water is too scarce or expensive (Belder et al. 2004). However, this aerobic rice production has led to a dramatic

Current address for S. Denil: Institute of Medical Biology, A*STAR 8A Biomedical Grove, \#06-08 (Immunos), Singapore 138648.

Corresponding author: T. Kyndt; E-mail: tina.kyndt@ugent.be

*The $\boldsymbol{e}$-Xtra logo stands for "electronic extra" and indicates that two supplementary figures and four supplementary tables are published online.

This article is in the public domain and not copyrightable. It may be freely reprinted with customary crediting of the source. The American Phytopathological Society, 2017. build-up of soil-borne pathogens, root-knot nematode (RKN) M. graminicola populations among them (De Waele and Elsen 2007; Kreye et al. 2009). This RKN is frequently found associated with cereals as well as other grasses and dicotyledonous plants, including many weeds commonly found in rice fields that may constitute a major reservoir of nematodes (Rich et al. 2009). Infective second-stage juveniles (J2) of M. graminicola invade rice roots just behind the root tip (Bridge et al. 2005). After moving towards the root tips, they induce a feeding site in the vascular tissue, called giant cells, and this causes the development of hook-like galls in which the nematodes complete their life cycle (Mantelin et al. 2017). Although this nematode is the most important pathogen in southeast Asian aerobic rice culture, it can also cause significant yield reductions in lowland and deepwater rice (Mantelin et al. 2017).

In agricultural fields, pathogens and parasites are never present as isolated organisms. Plants are challenged by many stresses at once, and the effect of one stress factor can have either positive or negative effects on subsequent or concomitant challenge by another stress factor. For example, below-ground feeding organisms such as insects, nematodes, root pathogens, and ectomycorrhizal fungi are known to influence the concentration of above-ground plant defense compounds, leading to an impact on the susceptibility of the above-ground tissues to subsequent pathogen attack (Wondafrash et al. 2013). Therefore, studies using systemic tissues can provide a broad perspective on plant health.

The study by Hofmann et al. (2010) was one of the first showing that nematode infection causes dramatic changes in metabolite profiles in systemic root and shoot tissues. In addition to the direct negative effect that nematodes have on plants, such as local root damage and loss of nutrients caused by nematodefeeding, defense responses and metabolite changes in systemic tissues are very energy- and nutrient-intensive for the hosts, and all these factors lead to reduced biomass production and crop yield losses. Indeed, our own transcriptome analysis on above-ground tissues of Hirschmanniella oryzae-infected rice plants showed a significant repression of genes involved in chlorophyll biosynthesis, which was confirmed by chlorophyll measurements in the shoot tissues (Kyndt et al. 2014). Next to that, genes involved in the growth-promoting brassinosteroid pathway, amino acid production, and the isoprenoid and shikimate pathways were also negatively affected upon root infection by this migratory nematode, potentially compromising growth and yield of the rice plants (Kyndt et al. 2014). 
Considering the RKN $M$. graminicola, our research group has previously investigated the role of the major hormone-related defense pathways, i.e. the salicylate (SA), ethylene (ET), and jasmonate (JA) pathways, in systemically induced defense, and we have shown that the JA pathway modulated by the ET pathway plays a pivotal role (Nahar et al. 2011). To overcome the plant defense system, the nematode seems to have acquired mechanisms to suppress the SA-, JA-, or ET-based root defense barriers, as detected in transcriptome analyses on galls (Kyndt et al. 2012a) and giant cells (Ji et al. 2013). This local suppression is accompanied by a systemic effect on plant immunity, in which quantitative reverse transcription-polymerase chain reaction (qRTPCR) of defense-related genes revealed a downregulation of the majority of these genes in above-ground tissues early upon RKN infection (Kyndt et al. 2012b).

This manuscript sets out to investigate the hypothesis that below-ground RKN attack is correlated with a changed plant immune system, which will predispose rice plants to aboveground attack by pathogens like, for instance, rice blast. Rice blast, caused by the ascomycete Magnaporthe oryzae (anamorph: Pyricularia oryzae) is the most destructive fungal rice disease worldwide, causing grain yield losses as high as 30\% per field (Skamnioti and Gurr 2009) and even up to $100 \%$, as noted in a recent outbreak in Brazil (Prabhu et al. 2009). This disease occurs in every rice-growing area in the world, and it is estimated that each year an amount of rice is destroyed by rice blast disease that is sufficient to feed 60 million people (Zeigler et al. 1994). After a high-throughput sequencing analysis of the transcriptional changes in above-ground tissues of RKN-infected rice, we demonstrate that $\mathrm{RKN}$-infected plants become more susceptible to blast infection. A detailed metabolic analysis of oxidative stress responses and hormonal balances is provided, in order to provide insights into the complex interaction between both pathogens in rice.

\section{RESULTS}

\section{Systemic transcriptome changes upon RKN infection in rice.}

The transcriptome of above-ground tissue of RKN-infected plants was analyzed at two time points, i.e., 3 and 7 days after infection (dai), and was compared with corresponding shoot tissues of healthy control plants sampled at the same time point. For each time point and treatment, two independent biological replicates, containing a pool of six different plants, were analyzed, using RNA-sequencing. The plant material sampled and analyzed here derives from the same experiments as the data described by Kyndt et al. (2014), which investigated the systemic changes in rice plants infected with another nematode species (Hrschmanniella oryzae). Here, we used four of these previously published control samples and compared with four newly sequenced samples of shoots of M. graminicola (RKN)-infected plants. The data have been submitted to the Gene Expression Omnibus (GEO) repository (GSE89449). The reads were aligned against the whole reference genome sequence of $\mathrm{cv}$. Nipponbare (MSU7.0) and, in total, $78.7 \%$ of the sequenced reads could be mapped (Supplementary Table S1). The total length of sequenced nucleotides was more than six trillion bases, representing 17-fold coverage of the rice genome sequence. Comparative gene expression profiling was performed by Gene Set Enrichment, pathway mapping, and statistical analysis of differential gene expression between infected and uninfected tissues, using a false discovery rate (FDR) of 0.05 as cut-off.

Differential expression at 3 dai. At the 3 -dai time point, 6,450 genes were significantly differentially expressed (FDR < $0.05)$ when comparing shoots of $\mathrm{RKN}$-infected with control plants, among which 474 novel transcriptionally active regions
(nTARs). Among the 6,121 downregulated genes, there were nine members of the somatic embryogenesis receptor kinase (SERK) family, all annotated as brassinosteroid-insensitive 1 -associated receptor kinase $1\left(\mathrm{BAK} 1 ; \log _{2} \mathrm{FC}\right.$ [fold change $]=$ -0.83 to -1.85$)$ next to $13 \mathrm{AP} 2$ domain-containing genes $\left(\log _{2} \mathrm{FC}=\right.$ -0.77 to -2.41$), 12$ harpin-induced protein 1 domain-containing genes $\left(\log _{2} \mathrm{FC}=-1.03\right.$ to -1.60$)$ and four 1-aminocyclopropane1 -carboxylate oxidase genes ( $\log _{2} \mathrm{FC}=-1.12$ to -2.39$)$, as well as phenylalanine-ammonia lyase $\operatorname{OsPAL7}\left(\log _{2} \mathrm{FC}=-1.3\right)$. Of the significantly downregulated genes, 19 are peroxidases $\left(\log _{2} \mathrm{FC}=\right.$ -1.0 to -2.5$), 14$ are thioredoxins $\left(\log _{2} \mathrm{FC}=-0.9\right.$ to -1.9$)$ and 30 are oxidoreductases $\left(\log _{2} \mathrm{FC}=-0.6\right.$ to -2.3$)$. Among the induced genes, jasmonate $O$-methyltransferase $\left(\log _{2} \mathrm{FC}=1.64\right)$ and two thionins, THION8 $\left(\log _{2} \mathrm{FC}=2.86\right)$ and THION3 $\left(\log _{2} \mathrm{FC}=\right.$ 2.20), were found (Supplementary Table S2).

Differential expression at 7 dai. At the 7-dai time point, only 21 genes were significantly differentially expressed (FDR < 0.05 ) in shoots of RKN-infected plants versus control plants, among which were four nTARs. The genes with the strongest suppression in shoots of nematode-infected plants at 7 dai are genes annotated as RNA polymerase sigma factor $\left(\log _{2} \mathrm{FC}=\right.$ $-2.50)$ and terpene synthase $\left(\log _{2} \mathrm{FC}=-2.29\right)$. Among the 14 induced genes, three genes are encoding proteins with oxidationreduction activity, a thioredoxin $\left(\log _{2} \mathrm{FC}=2.47\right)$, glutamate synthase $\left(\log _{2} \mathrm{FC}=2.78\right)$, and a peroxidase $\left(\log _{2} \mathrm{FC}=2.07\right)$.

General transcriptome changes in shoots of infected plants. To investigate consistent effects regardless of the time point after infection, further analyses were performed on the transcriptional changes occurring in infected versus control plants. At an FDR cut-off of $0.05,127$ genes were found to be consistently and significantly differentially expressed in the shoots after root infection with $M$. graminicola. Of these differentially expressed genes (DEGs), 95 are significantly downregulated while 32 show higher expression in infected plant shoots than in healthy plants. Among the downregulated genes, we detected genes involved in flavonoid and terpenoid biosynthesis (isoflavone reductase, $\log _{2} \mathrm{FC}=-2.64$; polyprenyl synthetase, $\log _{2} \mathrm{FC}=-1.77$ ), two members of the protein phosphatase $2 \mathrm{C}$ family ( $\log _{2} \mathrm{FC}=-1.81$ and -1.45$)$ functioning in multiple signaling pathways, and a gene encoding 1-aminocyclopropane-1carboxylate oxidase $\left(\log _{2} \mathrm{FC}=-1.24\right), 12$-oxophytodienoate reductase $\left(\log _{2} \mathrm{FC}=-1.13\right)$, and phenylalanine ammonia-lyase ( $\left.\log _{2} \mathrm{FC}=-1.16\right)$. Among the induced genes are genes encoding phytoene synthase $\left(\log _{2} \mathrm{FC}=1.03\right)$, involved in carotenoid biosynthesis, a lipoxygenase $\left(\log _{2} \mathrm{FC}=0.93\right)$, and a sucrose transporter $\left(\log _{2} \mathrm{FC}=1.13\right)$, as well as many unknown proteins. Next to these, 22 nTARs were found to be differentially expressed in this tissue versus shoots from uninfected plants, among which expression levels for 10 are lower and 12 are higher in shoots of infected plants versus control plants.

Parametric Gene Set Enrichment Analysis of all the infected versus uninfected plants revealed that the expression levels of 150 significantly enriched Gene Ontology (GO) terms, among which 'cellular process' and 'metabolic process', are all lower in the shoots of infected plants in comparison with healthy plants (Supplementary Fig. S1).

All differential expression patterns were mapped onto rice gene categories (called 'bins') in MapMan (Thimm et al. 2004) (Fig. 1A). Using the Wilcoxon signed rank (WSR) test implemented in MapMan, the gene categories enriched in DEGs were evaluated. In the category 'metabolism' (Fig. 1A; Table 1), 30 bins were significantly influenced by the infection $(P<0.001)$, among them, primary metabolic pathways like photosynthesis, lipid metabolism, carbohydrate (CHO) metabolism, and cell wall, as well as redox and secondary metabolism. Specifically, secondary metabolism was changed in the phenylpropanoids, isoprenoids (mevalonate and carotenoids), and amino acid metabolism-chorismate synthesis 
pathways (Fig. 1B; Table 2). When focusing on the category 'regulation' (Table 3), DEGs are attributed to the bins for mitogenactivated protein kinases, protein degradation and posttranslational modification, redox, regulation of transcription, and hormone metabolism (Fig. 1B; Table 3). Next to these bins, the category 'biotic stress' revealed significant changes in, for instance, hormone metabolism, bZIP, MYB, and AP2-transcription factors and pathogenesis-related (PR) proteins (Supplementary Table S3). Seeing the fact that plant immunity is strongly suppressed in the shoots of nematode-infected plants, we validated a set of consistently suppressed plant immunity genes, using qRT-PCR. For all genes, the suppression was confirmed at one or both time points (Supplementary Table S4). Noteworthy, differential expression levels were generally less strong and slightly more variable as what we had found with RNA-seq, which could be related to the fact that nematode infection synchronization was not performed in this validation experiment.

\section{Consequences for shoot susceptibility to Magnaporthe oryzae.}

Considering the fact that several genes involved in plant immunity (e.g., phenylpropanoids, isoprenoids, $O s B A K 1$ paralogues) appeared to be strongly influenced in the shoots of $\mathrm{RKN}$-infected

A
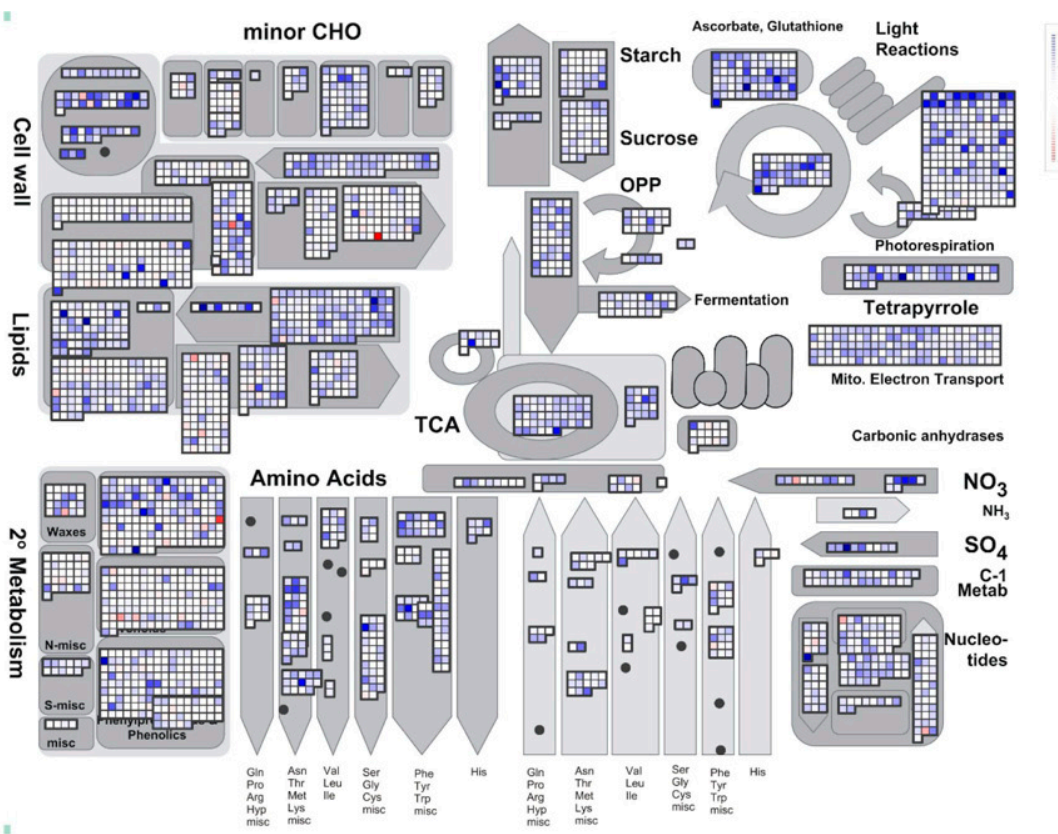

B

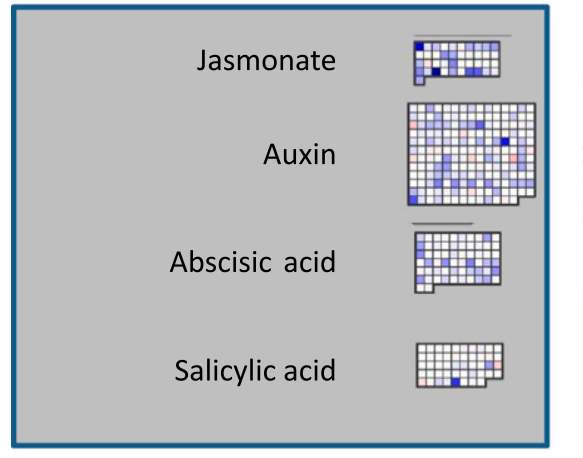

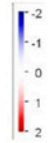
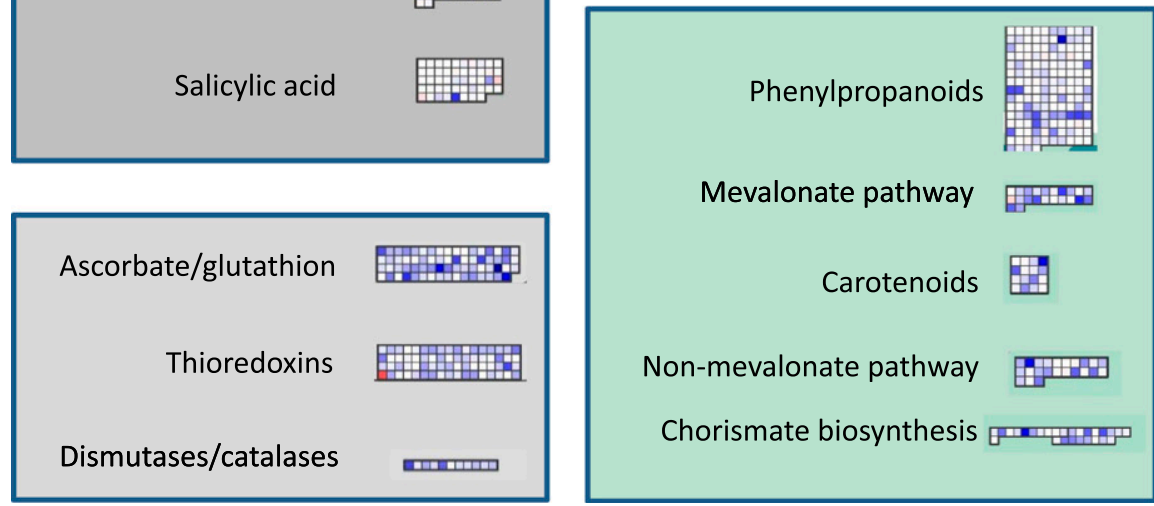

Fig. 1. Mapman visualization of the expression profiles of rice genes in above-ground tissues upon root-knot nematode infection. A, General overview of plant metabolism and $\mathbf{B}$, hormonal and other secondary metabolic pathways. The visualization shows the observed general differential expression patterns (average of 3 and 7 days after infection), based on the average $\log _{2}$-fold changes of mRNA levels in shoots of infected versus uninfected control plants. Each dot is one gene. Red dots indicate that the gene is upregulated in shoots of nematode-infected plants versus the corresponding healthy control plants, while blue indicates downregulation. 
plants, an above-ground infection with one of the most damaging foliar rice pathogens was performed. The hemibiotrophic fungus Magnaporthe oryzae (causal agent of rice blast) was inoculated on rice plants either 3 or 7 days after nematode inoculation (dai). Disease progress was evaluated one week after blast challenge, by counting the number of susceptible-type lesions on the second youngest leaf (Fig. 2A, B, and C) and quantifiying Magnaporthe oryzae DNA in the shoots by qPCR (Fig. 2D). When the interval between both inoculations was 3 days, the number of lesions $(n=$ 9) as well as the amount of Magnaporthe oryzae DNA in the shoots $(n=3)$ was significantly increased in inoculated compared

Table 1. Results of a MapMan-based Wilcoxon signed rank test showing groups of enriched genes ('bins') in the category 'metabolism' $(P<0.001)^{\mathrm{a}}$

\begin{tabular}{|c|c|c|c|}
\hline Bin & Name & Elements & $P$ value \\
\hline 1.1 & PS.lightreaction & 182 & $1.371 \mathrm{E}-25$ \\
\hline 11.1 & $\begin{array}{l}\text { Lipid metabolism.FA synthesis and FA } \\
\text { elongation }\end{array}$ & 107 & $8.013 \mathrm{E}-22$ \\
\hline 9 & $\begin{array}{l}\text { Mitochondrial electron transport / ATP } \\
\text { synthesis }\end{array}$ & 124 & $6.019 \mathrm{E}-20$ \\
\hline 21.2 & Redox.ascorbate and glutathione & 67 & $4.345 \mathrm{E}-18$ \\
\hline 10.1 & Cell wall.precursor synthesis & 52 & $2.781 \mathrm{E}-11$ \\
\hline 19 & Tetrapyrrole synthesis & 44 & 3.813E-11 \\
\hline 8.1 & TCA/org. transformation.TCA & 46 & $4.658 \mathrm{E}-11$ \\
\hline 1.3 & PS.calvin cycle & 43 & $2.120 \mathrm{E}-10$ \\
\hline 3.5 & Minor CHO metabolism.others & 49 & $1.658 \mathrm{E}-8$ \\
\hline 23.4 & $\begin{array}{l}\text { Nucleotide metabolism.phosphotransfer } \\
\text { and pyrophosphatases }\end{array}$ & 32 & $5.998 \mathrm{E}-8$ \\
\hline 11.3 & Lipid metabolism.Phospholipid synthesis & 65 & 8.567E-8 \\
\hline 11.8 & $\begin{array}{l}\text { Lipid metabolism."exotics" (steroids, } \\
\text { squalene etc) }\end{array}$ & 109 & $1.382 \mathrm{E}-6$ \\
\hline 4 & Glycolysis & 49 & $2.210 \mathrm{E}-6$ \\
\hline 16.2 & Secondary metabolism.phenylpropanoids & 144 & $2.536 \mathrm{E}-6$ \\
\hline 25 & C1-metabolism & 29 & $2.779 \mathrm{E}-6$ \\
\hline 10.5 .1 & Cell wall.cell wall proteins.AGPs & 25 & $6.139 \mathrm{E}-6$ \\
\hline 13.1.3.4 & $\begin{array}{l}\text { Amino acid metabolism.synthesis. } \\
\text { aspartate family.methionine }\end{array}$ & 29 & 7.974E-6 \\
\hline 2.1 .2 & Major CHO metabolism.synthesis.starch & 31 & $3.724 \mathrm{E}-5$ \\
\hline 16.1 & Secondary metabolism.isoprenoids & 150 & $3.835 \mathrm{E}-5$ \\
\hline 8.2 & $\begin{array}{l}\text { TCA/org. transformation.other organic } \\
\text { acid transformations }\end{array}$ & 17 & $4.065 \mathrm{E}-5$ \\
\hline 23.2 & Nucleotide metabolism.degradation & 40 & $5.297 \mathrm{E}-5$ \\
\hline 13.1.6.1 & $\begin{array}{l}\text { Amino acid metabolism.synthesis. } \\
\text { aromatic aa.chorismate }\end{array}$ & 18 & $7.731 \mathrm{E}-5$ \\
\hline 11.10 & Lipid metabolism.glycolipid synthesis & 12 & $8.633 \mathrm{E}-5$ \\
\hline 23.3 & Nucleotide metabolism.salvage & 39 & $1.163 \mathrm{E}-4$ \\
\hline 10.5 .4 & Cell wall.cell wall proteins.HRGP & 10 & $2.748 \mathrm{E}-4$ \\
\hline 2.2 .1 & $\begin{array}{l}\text { Major CHO metabolism.degradation. } \\
\text { sucrose }\end{array}$ & 42 & $2.812 \mathrm{E}-4$ \\
\hline 1.2 & PS.photorespiration & 21 & $3.539 \mathrm{E}-4$ \\
\hline 10.2 & Cell wall.cellulose synthesis & 60 & $4.593 \mathrm{E}-4$ \\
\hline 5 & Fermentation & 27 & $7.260 \mathrm{E}-4$ \\
\hline 10.5 .3 & Cell wall.cell wall proteins.LRR & 15 & 7.404E-4 \\
\hline
\end{tabular}

a The number of genes in this group, as well as the Benjamin Hochberg corrected $P$ value is provided for each bin.

Table 2. Results of a MapMan-based Wilcoxon signed rank test showing groups of enriched genes ('bins') in the category 'secondary metabolism' $(P<0.001)^{\mathrm{a}}$

\begin{tabular}{|c|c|c|c|}
\hline Bin & Name & Elements & $P$ value \\
\hline 16.2 & Secondary metabolism.phenylpropanoids & 144 & $2.536 \mathrm{E}-6$ \\
\hline 16.1.2 & $\begin{array}{l}\text { Secondary metabolism.isoprenoids. } \\
\text { mevalonate pathway }\end{array}$ & 22 & $1.027 \mathrm{E}-5$ \\
\hline 13.1.6.1 & $\begin{array}{l}\text { Amino acid metabolism.synthesis. } \\
\text { aromatic aa.chorismate }\end{array}$ & 18 & 7.731E-5 \\
\hline 16.1.4 & $\begin{array}{l}\text { Secondary metabolism.isoprenoids. } \\
\text { carotenoids }\end{array}$ & 16 & $2.135 \mathrm{E}-4$ \\
\hline 16.1.1 & $\begin{array}{l}\text { Secondary metabolism.isoprenoids. } \\
\text { non-mevalonate pathway }\end{array}$ & 23 & $6.2297 \mathrm{E}-4$ \\
\hline
\end{tabular}

${ }^{\text {a }}$ The number of genes in this group, as well as the Benjamin Hochberg corrected $P$ value is provided for each bin. to non-nematode inoculated control plants (Kruskal-Wallis followed by Mann-Whitney, $P<0.05$ ). When the interval between both inoculations was 7 days, only the number of lesions was significantly increased while the amount of fungal DNA was not significantly different between nematode-inoculated and control plants. These data indicate that RKN inoculation predisposes the rice plant to faster rice blast disease progression, mainly when the time interval between both inoculations is short.

\section{The role of oxidative stress.}

Since significant transcriptional changes were recorded in genes involved in the redox status of the plant (Table 3; Fig. 1B), an independent validation experiment was executed to analyze levels of $\mathrm{H}_{2} \mathrm{O}_{2}$ and lipid peroxidation (as a measure of oxidative stress) in the shoots of infected plants. Results showed that, at both 3 and 7 dai, $\mathrm{H}_{2} \mathrm{O}_{2}$ levels are significantly increased in the shoots of nematode infected plants $(n=4$; Kruskal-Wallis followed by Mann-Whitney, $P<0.05$ ) (Fig. 3A). Also, malondialdehyde (MDA), a measure of lipid peroxidation, was significantly higher for the shoots of nematode-infested plants $(n=4$; Kruskal-Wallis followed by Mann-Whitney, $P<0.05$ ) (Fig. 3B).

Based on this observation, we hypothesized that the higher oxidative stress in the shoots might be responsible for increased blast susceptibility. To test our hypothesis, a double infection experiment was done on a vitamin $\mathrm{C}$-deficient rice line (vtc), a TOS17 insertional mutant (ND6172) for a GDP-D-mannose-3', $5^{\prime}$ epimerase gene, which contains 20 to $30 \%$ lower ascorbate levels than the wild-type 'Nipponbare' (Frei et al. 2012). Ascorbate is an antioxidant and this mutant is, hence, known to accumulate significantly higher levels of $\mathrm{H}_{2} \mathrm{O}_{2}$ upon stress (Höller et al. 2014). A 3-day interval between infections was selected, since this provided the strongest increase in shoot blast susceptibility (Fig. 2).

Results of the infection experiment revealed that the $v t c$ mutant is equally as susceptible to Magnaporthe oryzae infection as the wild type, with a similar number of lesions and fungal DNA accumulation in the leaves (Fig. 3C, D, E, and F). When the vtc mutant was inoculated with RKN 3 days prior to blast infection, an enhanced susceptibility to blast infection was recorded, with an even slightly enhanced effect on sporulating lesions than the effect observed in the wild-type plants (Fig. 3C, D, E, and F). This observation shows that the increased oxidative stress levels in the shoots are unlikely to cause the increased levels of blast infection in the RKN-infected plants.

\section{The role of hormonal disturbances.}

As the transcriptome data also revealed significant changes in hormone metabolism (Table 3; Fig. 1B), we hypothesized that hormonal disturbances could be responsible for the increased

Table 3. Results of a MapMan-based Wilcoxon signed rank test showing groups of enriched genes ('bins') in the category 'regulation' $(P<0.001)^{\mathrm{a}}$

\begin{tabular}{llrc}
\hline Bin & \multicolumn{1}{c}{ Name } & Elements & $\boldsymbol{P}$ value \\
\hline 30.2 & Signaling.receptor kinases & 2,101 & $0.000 \mathrm{E}+00$ \\
29.5 & Protein.degradation & 1,674 & $1.841 \mathrm{E}-90$ \\
27.3 & RNA.regulation of transcription & 3,016 & $2.003 \mathrm{E}-68$ \\
30.5 & Signaling.G-proteins & 217 & $5.258 \mathrm{E}-40$ \\
29.4 & Protein.postranslational modification & 1,172 & $1.088 \mathrm{E}-38$ \\
30.3 & Signaling.calcium & 235 & $4.489 \mathrm{E}-25$ \\
21.2 & Redox.ascorbate and glutathione & 67 & $4.345 \mathrm{E}-18$ \\
21.1 & Redox.thioredoxin & 68 & $2.397 \mathrm{E}-13$ \\
30.4 & Signaling.phosphinositides & 51 & $2.539 \mathrm{E}-09$ \\
17.7 & Hormone metabolism.jasmonate & 41 & $1.797 \mathrm{E}-05$ \\
17.2 & Hormone metabolism.auxin & 178 & $4.269 \mathrm{E}-05$ \\
30.6 & Signaling.MAP kinases & 35 & $7.226 \mathrm{E}-05$ \\
21.6 & Redox.dismutases and catalases & 11 & $9.322 \mathrm{E}-05$ \\
17.1 & Hormone metabolism.abscisic acid & 62 & $6.942 \mathrm{E}-04$ \\
\hline
\end{tabular}

a The number of genes in this group, as well as the Benjamin Hochberg corrected $P$ value is provided for each bin. 
susceptibility of RKN-infected plants towards blast infection. First, the internal levels of four different plant hormones, namely, abscisic acid (ABA), indole acetic acid (IAA), SA, and JA were investigated in infected plants, at different time points, upon single (RKN or blast) and double (RKN + blast) infections. Hormone levels in root systems as well as shoot tissues were analyzed. Depending on the site where the pathogen (RKN or blast) attacks the plant, these can be considered as local or systemic tissues. A timeline showing the moments of inoculation and sampling is visualized in Supplementary Fig. S2. All data are based on three biological replicates consisting of a pool of three individual plants, and statistics were done using KruskalWallis, followed by Mann-Whitney $(\alpha=0.05)$

Hormone profiles in roots. Figure 4 shows that, in roots 3 days after RKN infection, a significant increase of SA was detected. Parts of these plants were co-inoculated with blast and, one day later, the hormone levels were measured again. At this time point, the root IAA and SA levels slightly decreased whereas JA and ABA levels were unchanged. Seven days after single RKN infection, the SA levels in roots were back to basal levels, but these roots accumulated significantly more ABA. When coinoculating these plants with blast and measuring hormones one day later (M. graminicola 8 dai + blast 1 dai), root SA levels significantly increased.

Hormone profiles in shoots. When focusing on shoots (Fig. 5 ), only levels of IAA increased significantly in the systemic tissues 3 days after RKN infection. One day after single blast infection, a significant drop in ABA levels, a slight increase in
IAA, and a strong increase in JA levels were observed. When the plants were preinoculated with nematodes, and applying a 3-day interval (M. graminicola 4 dai + blast 1 dai), JA levels increased to even higher levels than in single blast-inoculated plants, while ABA levels were significantly decreased in comparison with uninfected or single RKN-infected plants.

At 7 days after single RKN infection, ABA levels were not significantly affected in the shoot. Upon single blast infection, we again observed a strong increase in JA levels and a slight increase in IAA levels. In double-inoculated plants, with a 7day interval (M. graminicola 8 dai + blast 1 dai), a significant drop in ABA levels and an increase in IAA and JA levels was detected, in comparison with uninfected or single-infected plants.

Based on the observation that IAA is significantly accumulating in systemic tissues of RKN-infected plants at 3 dai, when the strongest effect on blast susceptibility was observed (Fig. 2), a double-infection experiment was done on the auxin-deficient transgenic line with $O s G H 3.1$ overexpression (GH3.1ox) in comparison with its wild type, 'Bomba' (Domingo et al. 2009). This transgenic line overexpresses the OsGH3.1 gene, which is responsible for auxin conjugation. As a result, it contains reduced levels of free auxin, and previous research showed that this line is significantly less susceptible to Magnaporthe oryzae (Domingo et al. 2009).

Results of the infection experiment confirmed that the GH3.1ox line is significantly less susceptible to Magnaporthe oryzae infection compared with the wild type (Fig. 6). When
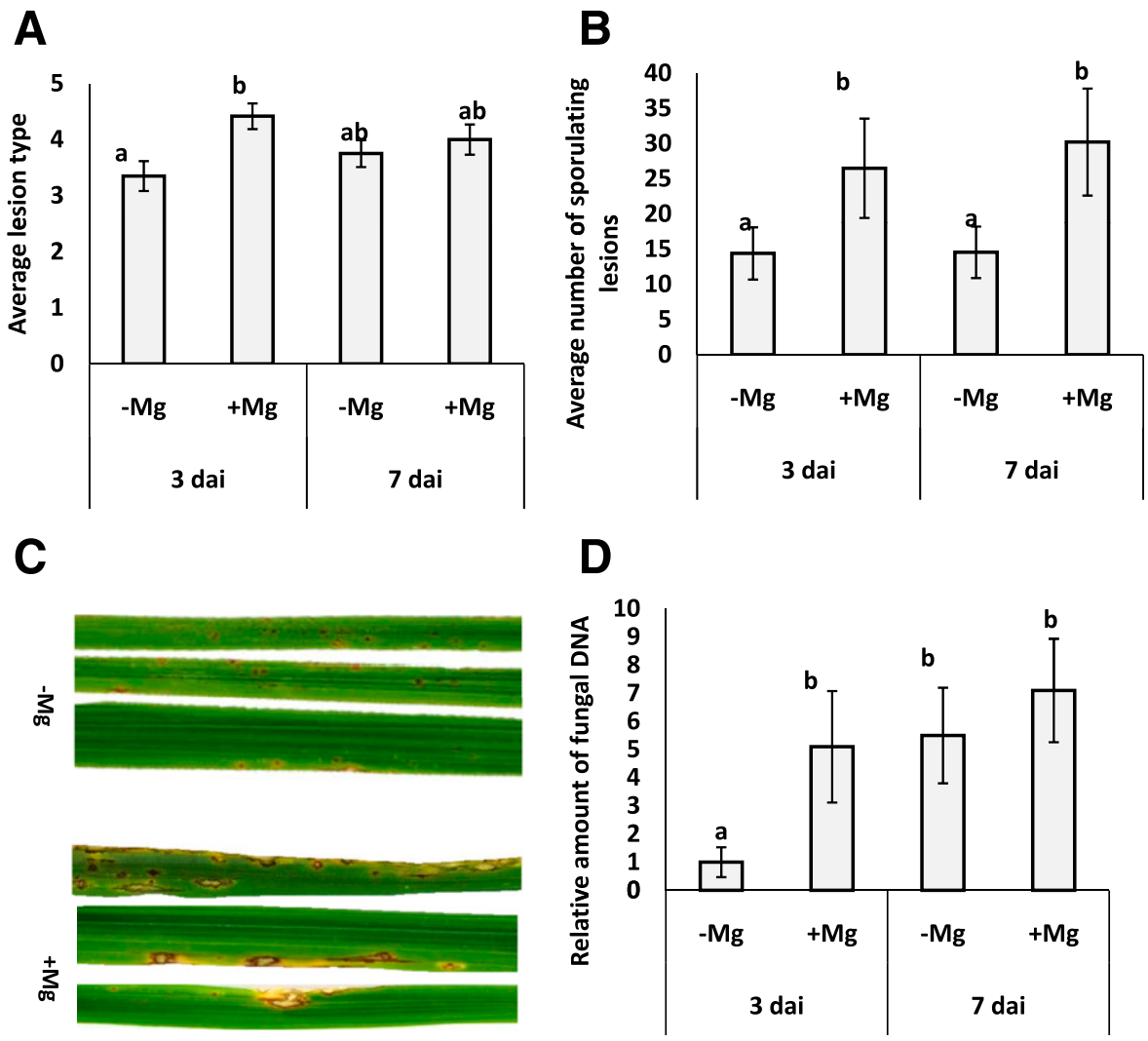

Fig. 2. Effect of nematode infestation on susceptibility of rice to the hemibiotrophic fungus Magnaporthe oryzae. Roots of rice cultivar Nipponbare were infested with Meloidogyne graminicola $(+M g) 3$ or 7 days before challenge with Magnaporthe oryzae. Control plants $(-\mathrm{Mg})$ were treated with water. Plant leaves were challenged at the four-leaf stage by spraying a spore suspension of the virulent Magnaporthe oryzae isolate VT7 at $5 \times 10^{4}$ conidia per milliliter. One week after challenge, disease was rated. A, Average lesion type scored on a scale of 0 to 6 , B, average number of sporulating lesions on the second youngest leaf, $\mathbf{C}$, blast symptoms on leaves at 3 days after infection (dai), and D, relative amount of DNA of Magnaporthe oryzae VT7 in leaves of rice plants preinoculated with nematode $(+\mathrm{Mg})$ or mock inoculated $(-\mathrm{Mg})$. Values are shown relative to the control treatment (-Mg, 3 dai, level set at 1$)(\mathrm{A}$ and $\mathrm{B})$. Values presented are average \pm standard error $(\mathrm{SE})$ of at least nine plants. Different letters indicate statistically significant differences according to nonparametric tests (Kruskal-Wallis followed by Mann-Whitney, $\alpha=0.05$ ). In $\mathrm{D}$, values are the average \pm SE of three biological replicates, each consisting of three plants. 
the GH3.10x line was inoculated with RKN, 3 days prior to blast infection, no enhanced susceptibility to blast infection was recorded, in contrast to the 'Bomba' wild type (Fig. 6). These data show that the increased blast susceptibility of $\mathrm{RKN}$-infected plants is at least partly dependent on auxin accumulation.

\section{DISCUSSION}

Outbreaks of rice blast disease are a serious and recurrent problem in all rice-growing regions of the world and the disease is extremely difficult to control (Talbot 2003). Although efficiently controlled by flooding in the past, rice production systems shifting towards reduced water usage are becoming more and more vulnerable to soil-borne pathogens (Kreye et al. 2009). In these aerobic and upland rice production systems, the RKN $M$. graminicola and rice blast are known to co-occur (Prasad 2011). In this manuscript, we provide evidence that root infection by these nematodes predisposes the rice plant to blast disease. After a comprehensive transcriptome analysis, biochemical analyses of oxidative stress and hormone profiling, we conclude that this synergism is partly dependent on increased auxin levels in rice shoot tissues upon nematode attack, aggravating blast disease progression.

Our own previous qRT-PCR analyses (Kyndt et al. 2012b), provided the basis for the current study. There, shoots of RKNinfected plants at 3 dai revealed a strong suppression of SA, JA, and ET biosynthesis genes as well as $P R$ genes (Kyndt et al. $2012 b$ ). Similar observations were made by Hamamouch et al. (2011) in RKN-infected Arabidopsis. Interestingly, our current mRNA-seq data not only confirmed repression of defense pathways but, also, revealed a suppression of primary and other secondary metabolic pathways in the shoots of RKN-infected plants.

In contrast, shoot tissue of Arabidopsis plants infected with the cyst nematode Heterodera schachtii showed higher expression of SA and JA marker genes than control plants from 5 through 14 dai (Hamamouch et al. 2011) and defense genes were also activated in shoots of Hirschmaniella oryzae-infected plants (Kyndt et al. 2014). Nevertheless, this last study also provided evidence for primary metabolic suppression in the infected plants. This illustrates that, although nematode infection has

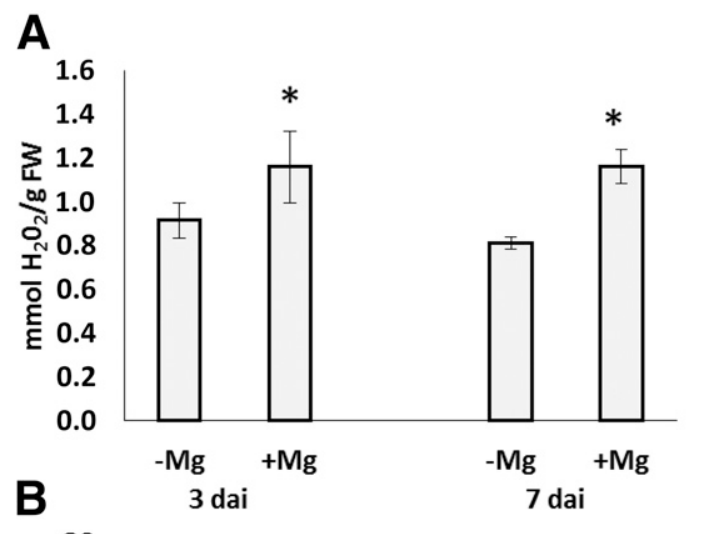

C
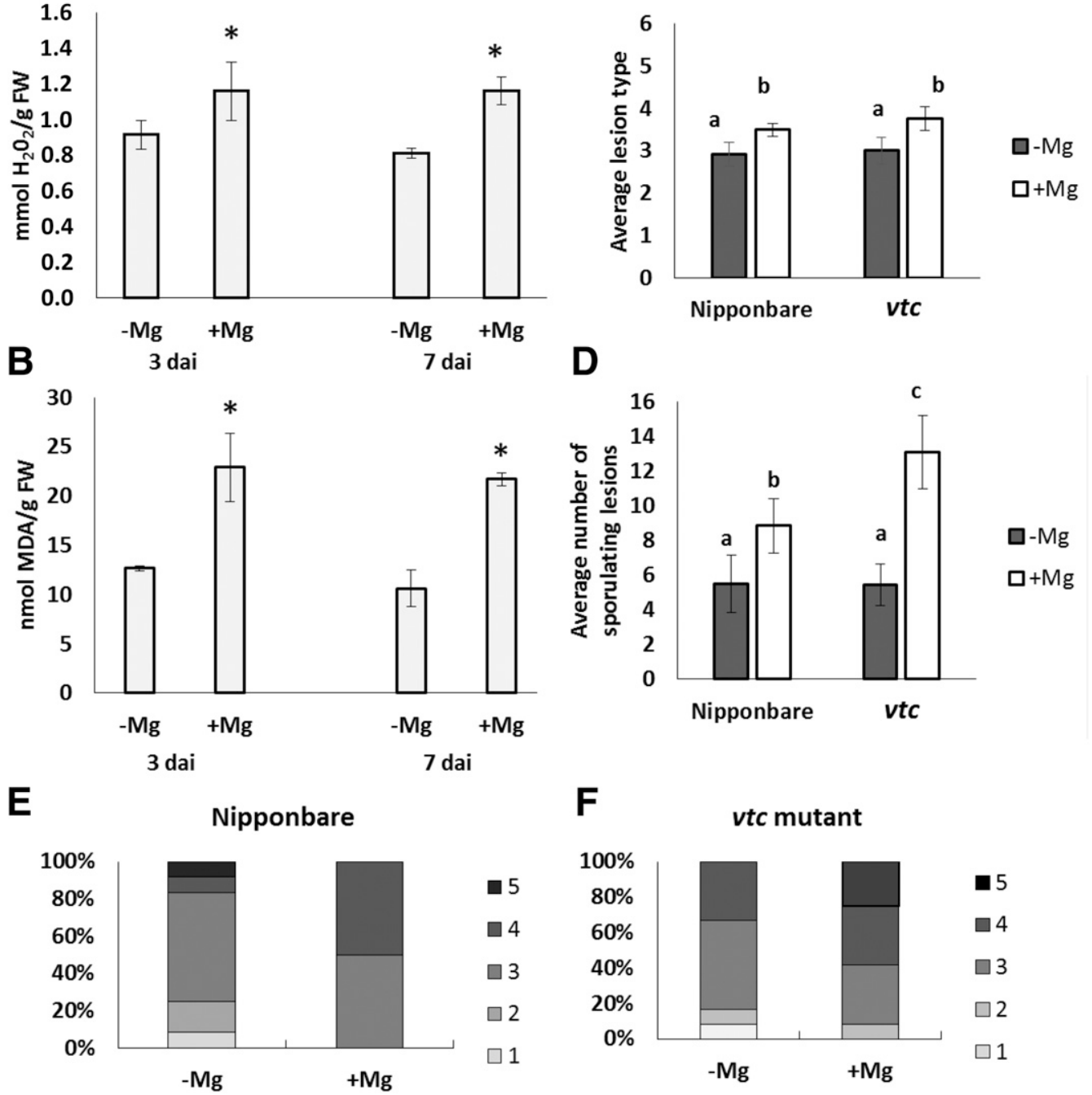

Fig. 3. Effect of nematode infestation on oxidative stress responses in the shoots of rice. Roots of rice cultivar Nipponbare were infested with Meloidogyne graminicola $(+\mathrm{Mg})$ or mock-inoculated with water $(-\mathrm{Mg}) . \mathbf{A}, \mathrm{H}_{2} \mathrm{O}_{2}$ levels and $\mathbf{B}$, malondialdehyde (MDA) levels in the shoots at 3 and 7 days after infection (dai). C and D, Susceptibility of the shoots of wild-type 'Nipponbare' and the ascorbate deficient vitamin C mutant (vtc) towards Magnaporthe oryzae. Magnaporthe oryzae was inoculated at 3 dai. In C, average lesion type scored on a scale of 0 to 5 ; in D, average number of sporulating lesions on leaf 4 . E, Lesion score distribution on 'Nipponbare' and $\mathbf{F}$, lesion score distribution on the vtc mutant. Values presented are average \pm standard error of at least four plants per treatment. Different letters indicate statistically significant differences according to nonparametric tests (Kruskal-Wallis followed by Mann-Whitney, $\alpha=0.05$ ). 
no obvious above-ground symptoms, the plant is generally weakened by the parasitic activities on the root system and this is most likely the cause of the reported yield losses in infested rice fields (Bridge et al. 2005).
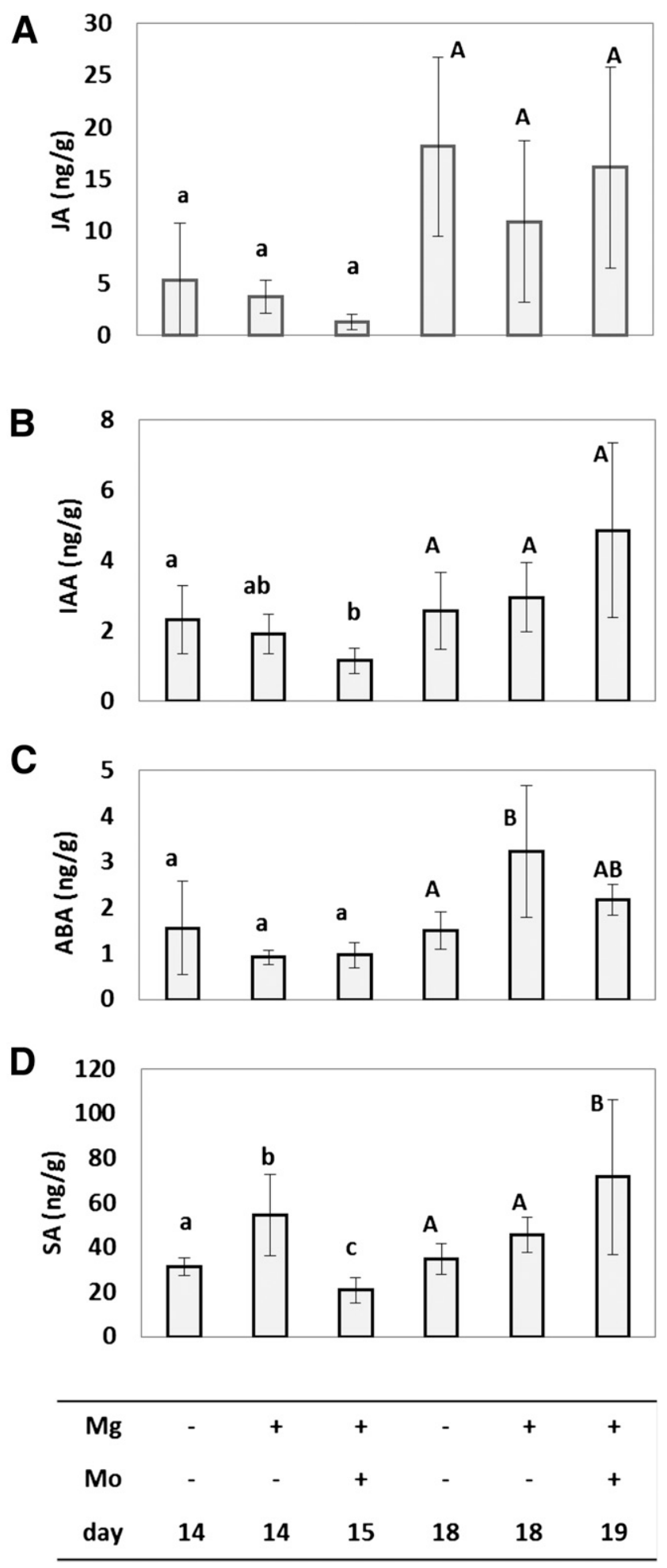

Fig. 4. Hormone levels (in nanograms per gram of fresh weight) in roots of single- and double-infected plants. Plants were infected with either Meloidogyne graminicola $(\mathrm{Mg})$, Magnaporthe oryzae $(\mathrm{Mo})$, or both and were sampled at different time points as indicated on the $x$ axis. A, Jasmonate (JA), B, indole 3-acetic acid (IAA), C, abscisic acid (ABA), and D, salicylate (SA) levels. Bars show the mean and standard deviation of three biological replicates. Different letters indicate statistically significant differences according to nonparametric tests (Kruskal-Wallis followed by Mann-Whitney, $\alpha=0.05$ ).
Defense repression and synergistic nematode-fungal interactions.

Endoparasitic nematodes are commonly reported to be involved in disease complexes with soil-borne fungal pathogens (Back et al. 2002). Synergism between RKNs and Fusarium wilt pathogens has already been described by Atkinson in 1892,
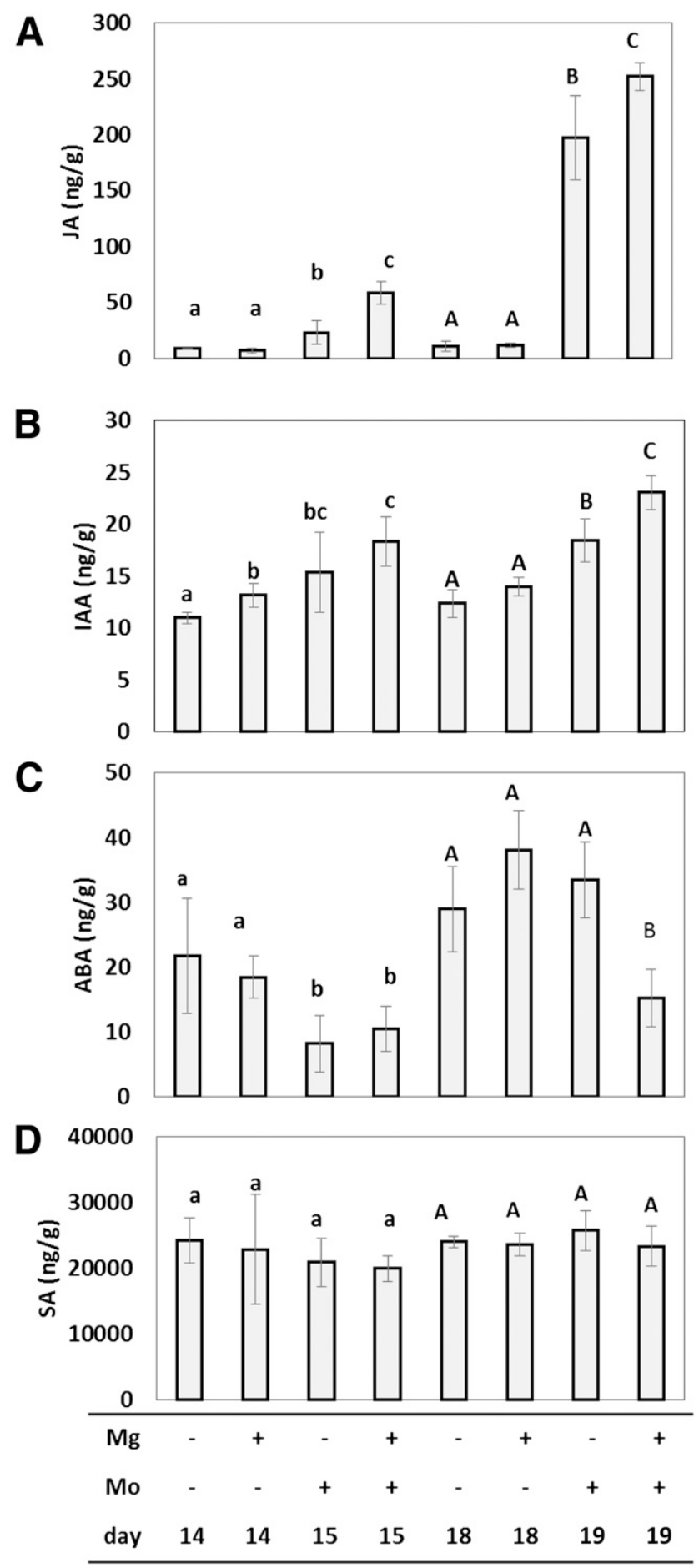

Fig. 5. Hormone levels (in nanograms per gram of fresh weight) in shoots of single- and double-infected plants. Plants were infected with either Meloidogyne graminicola $(\mathrm{Mg})$, Magnaporthe oryzae $(\mathrm{Mo})$, or both and were sampled at different time points as indicated in the $x$ axis. A, Jasmonate (JA), B, indole 3-acetic acid (IAA), C, abscisic acid (ABA), and D, salicylate (SA) levels. Bars show the mean and standard deviation of three biological replicates. Different letters indicate statistically significant differences according to nonparametric tests (Kruskal-Wallis followed by Mann-Whitney, $\alpha=0.05$ ). 
and, since then, similar interactions have been observed in different crops (Back et al. 2002). The mechanisms proposed to be responsible for nematode-fungal disease complexes are: i) wounding induced by nematode feeding, ii) nematode-induced physiological changes in the host, iii) modifications of the rhizosphere, or iv) reduced host resistance. Due to the different infection site, the here-observed systemic synergism between RKN and blast disease can only be attributed to either physiological changes in the host, reduced host resistance, or both. But also, in interactions between nematodes and other root pathogens, these changes appear to play an important role. For instance, Bowman and Bloom (1966) found that the tomato cultivars Rutgers and Homestead, previously resistant to F. oxysporum f. sp. lycopersici, developed symptoms of wilt during split-root experiments with $M$. incognita. Sidhu and Webster (1977), using root layering and grafting techniques, confirmed that a nematode-induced factor could be passed through a resistant scion (a graft from a resistant tomato cultivar) and render it susceptible to F. oxysporum f. sp. lycopersici.

Our transcriptome data, indeed, confirmed that there is a strong systemic effect of root parasitism on the above-ground defensive state of the plant. Since a general repression of defense pathways was observed, there must be a general common influencer of plant defense that is inactivated in these tissues. Intriguingly, among the DEGs at 3 dai, we found nine members of the SERK family, all annotated as rice BAK1 paralogues. OsBAK1 (LOC_Os08g07760.1), reported as being the closest rice homologue of AtBAK1 (Li et al. 2009), was not among these DEGs. Although its expression level was clearly lower in the shoots of infected plants, we lacked statistical power to detect a significant difference $\left(\log _{2} \mathrm{FC}=-1.46, \mathrm{FDR}=\right.$ 0.0538). AtBAK1 is a receptor kinase and a central regulator of
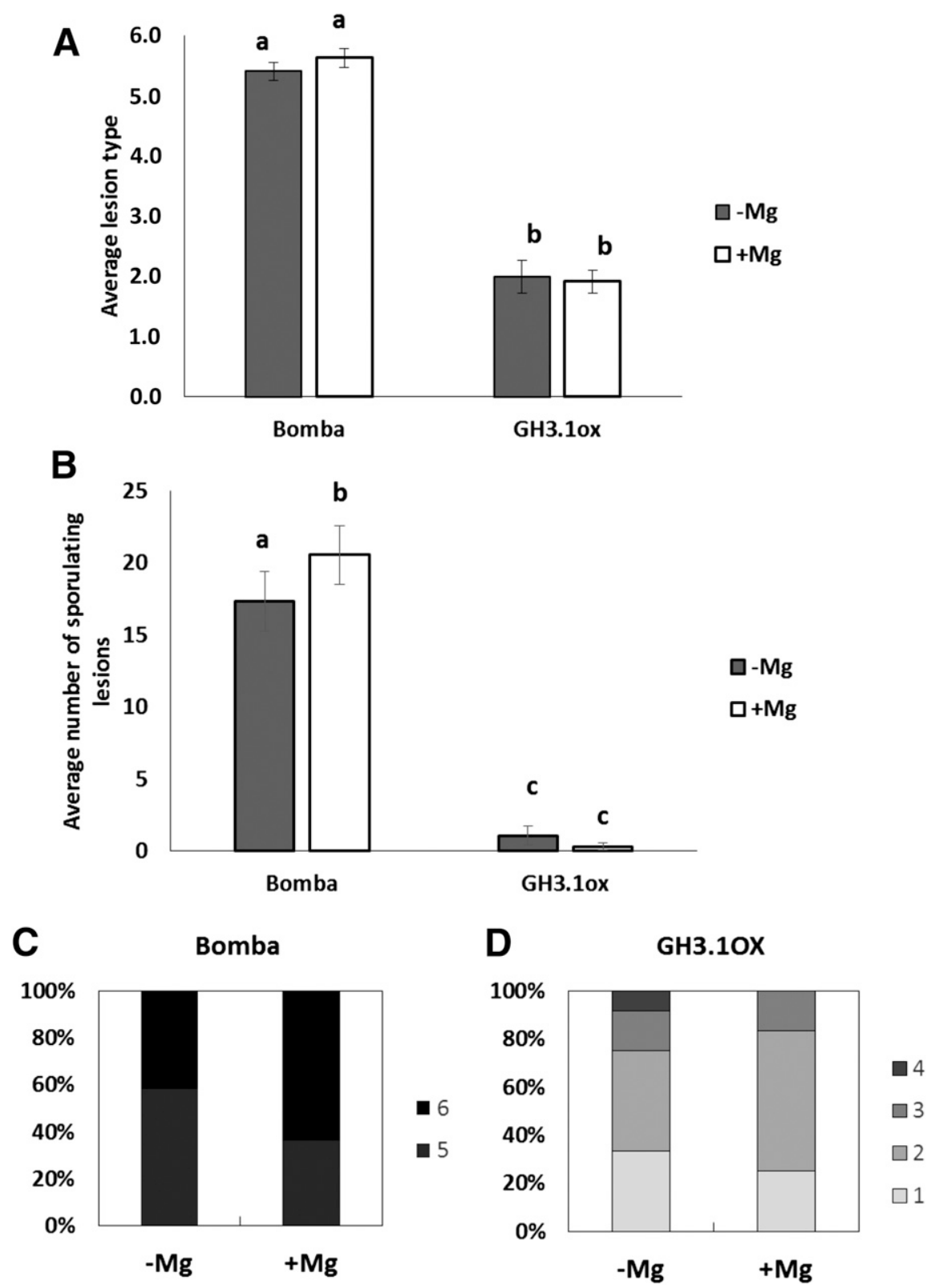

Fig. 6. Role of auxin in the synergistic interaction between Meloidogyne graminicola and Magnaporthe oryzae in rice. Roots of rice cultivar Nipponbare were infected with $M$. graminicola $(+M g)$ or mock-inoculated with water $(-\mathrm{Mg})$. Susceptibility of the shoots towards Magnaporthe oryzae was tested in the auxin deficient GH3.1 overexpression (GH3.1ox) transgenic line and its wild-type 'Bomba'. Magnaporthe oryzae was inoculated at 3 days after infection. $\mathbf{A}$, Average lesion type scored on a scale of 0 to $5, \mathbf{B}$, average number of sporulating lesions on the second youngest leaf, $\mathbf{C}$, lesion score distribution on 'Bomba', and D, lesion score distribution on the GH3.10x line. Values presented are average \pm standard error of at least 12 plants per treatment. Different letters indicate statistically significant differences according to nonparametric tests (Kruskal-Wallis followed by Mann-Whitney, $\alpha=0.05$ ). 
pattern-triggered immunity (PTI), which is known to be recruited by PTI receptors at the plasma membrane. Interestingly, transgenic OsBAK1 RNAi rice plants, in which the expression of $O s B A K 1$ as well as multiple other $O s S E R K$ genes was reduced, showed enhanced susceptibility to Magnaporthe oryzae (Park et al. 2011). Although further confirmation is needed, we hypothesize that the general repression of SERK/BAK1 gene family members is at least partially responsible for the enhanced susceptibility of the RKN-infected plants towards blast disease. Further investigations in this direction are worthwhile to explore.

\section{Oxidative stress in systemic tissues of RKN-infected plants.}

Transcriptome data as well as increased $\mathrm{H}_{2} \mathrm{O}_{2}$ and lipid peroxidation levels indicate that plants infected with RKN suffer from oxidative stress. For instance, genes involved in the ascorbate/glutathione cycle, thioredoxins, and dismutases/ catalases were generally repressed in above-ground tissues upon RKN attack. Based on these observations, we hypothesized that an accumulation of reactive oxygen species could be influencing blast infection in the shoots. Noting that NahG plants, which accumulate more $\mathrm{H}_{2} \mathrm{O}_{2}$, are more susceptible to blast (Yang et al. 2004), we were expecting a higher blast susceptibility in an ascorbate-deficient mutant, which also contains increased levels of $\mathrm{H}_{2} \mathrm{O}_{2}$ (Frei et al. 2012). Contradicting this hypothesis, the ascorbate-deficient mutant was equally as susceptible to Magnaporthe oryzae as the wild-type plants and RKN infection predisposes this ascorbate mutant to blast infection in a similar way as in the wild type. This demonstrates that changes in oxidative balance are not responsible for the enhanced blast susceptibility in RKN-infected plants.

\section{Lessons from hormone profiles.}

Although some shifts in expression profiles were observed, RKN inoculation of the roots had no major impact on the above-ground hormonal profile, except for a significant IAA increase at 3 dai. In contrast, hormonal levels appear to be more strongly influenced in rice shoots upon blast infection, with a clear accumulation of JA and a minor increase in IAA levels at 1 dai. However, when plants are inoculated with nematodes 3 or 7 days prior to blast infection, the blast-induced hormonal shift is boosted, enhancing JA and IAA accumulation and ABA repression.

Nematode or blast infection did not significantly affect the internal SA levels in the rice shoots. While roots do accumulate SA upon RKN infection, our data confirm the view that SA levels in rice shoots do not change significantly upon pathogen attack (Silverman et al. 1995). Noteworthy, in shoots, rice has significantly higher levels of SA than do dicots like Arabidopsis or tobacco. However, the SA analogue benzothiadiazole does induce resistance to Magnaporthe oryzae (Shimono et al. 2007), showing that SA signaling can still play an important role in the rice plant defense system. In the here-generated transcriptome data, only a minor, not significant, repression of the SA response gene OsWRKY45 expression was observed in shoots of RKN-infected plants at 3 dai. Hence, we conclude that SA signaling is probably not strongly involved in the observed synergism between both pathogens.

Our data showed a strong accumulation of JA at 1 dai in blast-infected plants. In contrast, Riemann et al. (2013) previously showed that JA-isoleucine but not JA increases at 1 and 2 days after blast infection. In our case, although also increased at day 15 , the JA accumulation was seen most strongly in the older plants (at day 19). Riemann et al. (2013) used 3- to 4week-old plants, and hence, the effect could vary depending on plant age. However, these contrasting observations could also be due to environmental conditions (e.g., light) or differences in Magnaporthe oryzae inoculum virulence. JA has an important role in plant defense against blast. Studies with JA-deficient lines and pharmacological inhibitor experiments have uncovered JA as a powerful activator of resistance against Magnaporthe oryzae (e.g., Mei et al. 2006; Riemann et al. 2013; Taniguchi et al. 2014; Yamada et al. 2012). Exogenous application of JA or overexpression of the JA-biosynthesis gene OsAOS2 increases resistance against rice blast (Mei et al. 2006). Jasmonate-deficient allene oxide cyclase mutants cpm2 and hebiba were shown to be susceptible to an incompatible, generally avirulent strain of Magnaporthe oryzae (Riemann et al. 2013), and rice Osjarl-2 mutants appeared more susceptible to blast fungus than wild-type plants (Shimizu et al. 2013). In the here-described results, RKN infection did not influence JA levels in the shoots, hence, changes in JA levels are most likely not responsible for the increased blast susceptibility of RKN-infected plants. Noteworthy, in this context, is the fact that the common idea that JA triggers resistance to necrotrophs and susceptibility to biotrophs is not corroborated by data obtained from research on rice-pathogen interactions, in which no dichotomy between the effectiveness of the JA pathway and the lifestyle of the invading pathogen has been observed (De Vleesschauwer et al. 2014).

Although ABA was increased at 7 dai in $\mathrm{RKN}$-infected roots, ABA levels were not significantly influenced in the aboveground tissues upon single RKN infection. Interestingly, ABA levels in shoots strongly dropped upon single blast infection in the younger plants (day 15) and in the double-infected plants at both time points (day 15 and 19). In two recent studies, ABA content was also measured in blast-infected tissue at 1 dai. Spence et al. (2015) found no significant differences with uninfected control plants, while Cao et al. (2016) detected a significant increase at $24 \mathrm{~h}$ postinfection (hpi) but no difference at 48 hpi. Generally speaking, ABA has a positive role in blast susceptibility, as exogenous ABA increases spore germination and appressoria formation (Spence et al. 2015) and application of ABA on rice plants suppresses rice resistance against Magnaporthe oryzae (Cao et al. 2016; Koga et al. 2004). This suggests that Magnaporthe oryzae-evoked changes in ABA levels are dependent on the infection stage and the age of the plants. Given the fact that ABA promotes blast susceptibility, the drop in shoot ABA levels cannot be responsible for the increased Magnaporthe oryzae susceptibility observed upon $\mathrm{RKN}$ infection in rice. Although further investigation is needed, we hypothesize that the here-observed drop in ABA upon blast infection is caused by a mutually antagonistic interaction between the JA and ABA pathways, as shown in Arabidopsis (Anderson et al. 2004) and in rice (Nahar et al. 2012).

Auxin is a negative influencer of disease resistance in rice (Yang et al. 2013). Constitutive expression of OsGH3.1, OsGH3.2, or $O s G H 3.8$, leading to reduced auxin levels, is correlated with enhanced resistance to Magnaporthe oryzae (Ding et al. 2008; Domingo et al. 2009; Fu and Wang 2011). Our data from the OsGH3.1ox line confirm these findings. Moreover, we show that RKN infection on this line does not promote blast infection, as it does in the wild type. This reveals that the blast-RKN synergism is at least partially dependent on free auxin levels in the shoots. Indeed, IAA is significantly accumulating in shoots of RKNinfected plants at 3 and at 1 dai, upon single blast infection. Upon double infection, an enhanced IAA increase is observed, correlating with an aggravated blast infection.

\section{Conclusion.}

The data provided in this paper, demonstrate that the general primary and secondary metabolisms of the rice plants are 
weakened upon infection with $M$. graminicola, predisposing the plant to other infections, such as, for instance, Magnaporthe oryzae. Our results show that this synergism is at least partly dependent on increased auxin levels in rice shoot tissues upon nematode attack, while changes in the host oxidative balance are not responsible for the enhanced blast susceptibility in RKN-infected plants.

\section{MATERIALS AND METHODS}

\section{Plant growth conditions and nematode infection.}

Oryza sativa 'Nipponbare' (GSOR-100, United States Department of Agriculture) was germinated on wet filter paper for 6 days at $30^{\circ} \mathrm{C}$, was transferred to sand absorbent polymer (SAP) substrate (Reversat et al. 1999), and was further grown at $26^{\circ} \mathrm{C}$, under a 16-h light and 8-h dark regime. The nematodes were extracted using a Baermann funnel from $M$. graminicolainfected rice plants cultured under the same conditions. Five days after transplanting in SAP, the plants were inoculated with 250 nematodes per plant or were mock-inoculated with tap water.

\section{Transcriptome analysis.}

One day after RKN inoculation, the plants were transferred to a hydroponic culturing system with Hoagland solution, to synchronize the infection process. Shoots were collected 3 and 7 dai. At each time point, two independent biological replicates, containing a pool of six different plants, were taken for RNA sequencing. As control, our already published sequencing data of shoot tissue of two independent biological replicates of uninfected plants, from the same batch of experiments, sampled at the same time points, and sequenced in the same run, were used (Kyndt et al. 2014).

RNA was extracted using the Qiagen RNeasy plant mini kit (Qiagen), with an additional sonication step after the addition of buffer RLT (Qiagen). RNA integrity was checked using the Agilent BioAnalyzer 2100 (Agilent). Approximately $2 \mu \mathrm{g}$ of total RNA was used for mRNA-Seq library construction, according to the manufacturer's recommendations (Illumina).

The multiplexing sequencing adapters provided in the Multiplexing sample preparation oligo kit (Illumina) were used. Size selection of the library was performed on a $2 \%$ agarose gel (Low-range ultra agarose; Biorad). The denatured library was diluted to a final concentration of $6 \mathrm{pM}$ and was loaded on a paired-end read flow cell (TruSeq v5 kit; Illumina). To minimize lane effects, the samples were multiplexed. Each sample was sequenced in duplicate in two different lanes. After cluster generation, the multiplexed library was sequenced on an Illumina genome analyzer IIx (36 cycles, paired end).

\section{Mapping reads to genome data and annotated transcripts.}

Reads were mapped to the Oryza sativa subsp. japonica reference genome (build MSU7.0) in two phases, using TopHat version 1.3.1 (Trapnell et al. 2009) and Cufflinks, version 1.0. (Trapnell et al. 2010). A detailed description of the workflow and settings used in the data analysis was given by Kyndt et al. (2012a).

\section{Calculation, normalization, and profiling of gene expression.}

RNA sequencing reads of control shoot tissues were already available in our previous GEO submission (GSE57707). For four new samples of infected rice plant tissue, sequenced reads were uploaded to GEO under accession GSE89449. The reads were processed analogously to the control samples, as previously described. Raw counts in canonical rice genes ("LOC_Os...") for both datasets were merged by gene identifier. The merged count table is also included in this submission.
Expression profiles were assessed using the $\mathrm{R}$ package "baySeq", version 1.5.1. (Hardcastle and Kelly 2010). To compensate for artificial differences in read distributions, the original library sizes were multiplied by additional normalization factors, calculated using the trimmed median of $\mathrm{M}$ values method described by Robinson and Oshlack (2010), with standard settings as implemented in the edgeR package (version 2.0.3). For statistical significance, a FDR cut-off of 0.05 was taken.

The expression level of each transcript for each condition was estimated as the FC of mapped reads relative to the controls. The FC was calculated as follows: reads were normalized as described earlier and were averaged over the biological replicates. Before calculating the base $2 \log$ of the ratio of these averages, the number of reads was increased by 1 in each group (to avoid 0 values).

\section{GO and enrichment analyses.}

GO analysis and GO enrichment were performed using agriGO (Du et al. 2010). Parametric analysis of gene set enrichment (PAGE) (Kim and Volsky 2005), based on differential gene expression levels $\left(\log _{2} \mathrm{FC}\right)$, was executed. BenjaminiHochberg FDR analysis was performed to adjust the PAGE $P$ values.

In addition, MapMan (Thimm et al. 2004) was used to visualize the expression of genes onto metabolic pathways and the WSR test (with FDR adjustment) was used to test the statistical significance of differential expression of these pathways. Based on potential functional importance and consistency of the differential expression profile, six genes were selected for validation in two independent biological samples, by qRT-PCR. For these experiments, no synchronization of the nematode infection was done. qRT-PCR was performed and analyzed as described by Kyndt et al. (2012b), using three technical replicates.

\section{Double infection with nematodes and blast.}

Plants were grown and inoculated with RKN as described above. At 3 or 7 dai, plant leaves were challenged by spraying a spore suspension of the virulent Vietnamese Magnaporthe oryzae isolate VT7 at $5 \times 10^{4}$ conidia per milliliter.

One week after blast challenge, disease was rated, using a 0 to 6 scale, based on the type and number of lesion on the second youngest leaves. In each experiment, at least nine plants were investigated per treatment and the whole experiment was independently repeated twice. The amount of fungal DNA in the leaves was quantified by real-time PCR, as described by Thuan et al (2006). DNA was extracted from three biological replicates, each consisting of a pool of three individual plants. A specific pair of DNA primers (forward, 5'-TAC GAG AGG AAC CGC TCA TTC AGA TAA TTA; reverse, 5' -TCA GCA GAT CGT AAC GAT AAA GCT ACT C), designed based on the 3' end of the Magnaporthe oryzae 28S rDNA gene, was used for the qPCR (Qi and Yang 2002).

\section{Biochemical assays.}

Hydrogen peroxide levels were determined according to Velikova et al. (2000). MDA levels were measured using the protocol described by Hodges et al. (1999). Shoot tissues (about $100 \mathrm{mg}$ ) were ground in liquid nitrogen and were dissolved in $0.1 \%$ (wt/vol) trichloroacetic acid. The homogenate was centrifuged at 14,000 rpm for $15 \mathrm{~min}$ using an Eppendorf centrifuge 5417R.

For hydrogen peroxide measurement, $60 \mu \mathrm{l}$ of the supernatant was added to $60 \mu \mathrm{l}$ of $10 \mathrm{mM}$ potassium phosphate buffer (pH 7.0) and $60 \mu \mathrm{l}$ of $1 \mathrm{M} \mathrm{KI}$. The absorbance of the supernatant was read at $\lambda_{\max }=390 \mathrm{~nm}$. The hydrogen peroxide content was calculated based on a standard curve made by measuring known hydrogen peroxide concentrations in the same assay. 
For MDA measurement, $0.25 \mathrm{ml}$ of the supernatant was added to reaction solution I (RSI; $0.01 \%$ [vol/vol] 2,6-di-tertbutyl-4-methylphenol in 20\% trichloroacetic acid) and $0.25 \mathrm{ml}$ was added to reaction solution II (RSI $+0.65 \%$ 2-thiobarbituric acid). The samples were heated in a hot water bath at $95^{\circ} \mathrm{C}$ for $30 \mathrm{~min}$. After cooling on ice, the samples were centrifuged and the absorbance was read at 440, 532, and $600 \mathrm{~nm}$. The MDA concentration was determined using the formulas described by Hodges et al. (1999).

For each treatment, four biological replicates were included, each consisting of a pool of at least three plants. The experiment was independently repeated, with similar results.

\section{Hormone measurements.}

At the indicated sampling times, whole root and shoot material was sampled from three biological replicates, each consisting of a pool of three individual plants. The material was homogenized using liquid $\mathrm{N}_{2}$ and was extracted at $-80^{\circ} \mathrm{C}$, using modified Bieleski solvent. After filtration and evaporation, chromatographic separation was performed on a U-HPLC system (Thermo Fisher Scientific) equipped with a Nucleodur C18 column $(50 \times 2 \mathrm{~mm} ; 1.8 \mu \mathrm{m}$ particle diameter $)$ and using a mobile phase gradient consisting of acidified methanol and water. Mass spectrometric analysis was carried out in selected-ion monitoring mode with a Q Exactive Orbitrap mass spectrometer (Thermo Fisher Scientific), operating in both positive and negative electrospray ionization mode at a resolution of 70,000 full width at half maximum. The detailed procedure will be described elsewhere (A. Haeck, K. Demeestere, G. Gheysen, and M. Höfte, unpublished).

\section{ACKNOWLEDGMENTS}

The Special Research Fund of Ghent University is acknowledged for their financial support in the BOF13/GOA/030 project. The authors also acknowledge the financial support (AUGE/11/016) from the Hercules Foundation of the Flemish Government for the UHPLC-Q-Exactive mass spectrometry equipment available at the EnVOC research group and used for hormone analysis. We thank L. De Smet and L. Harinck for their technical support. T. Kyndt has been supported by an FWO (Fonds Wetenschappelijk Onderzoek - Vlaanderen) postdoctoral fellowship. We also thank M. Frei (University of Bonn, Germany) and C. Domingo (Instituto Valenciano de Investigaciones Agrarias, Spain) for providing seeds of the rice vtc and GH3.10x lines, respectively.

\section{LITERATURE CITED}

Anderson, J. P., Badruzsaufari, E., Schenk, P. M., Manners, J. M., Desmond, O. J., Ehlert, C., Maclean, D. J., Ebert, P. R., and Kazan, K. 2004. Antagonistic interaction between abscisic acid and jasmonate-ethylene signaling pathways modulates defense gene expression and disease resistance in Arabidopsis. Plant Cell 16:3460-3479.

Atkinson, G. F. 1892. Some diseases of cotton. Page 65 in: Alabama Agricultural Experiment Station Bulletin 41. Auburn University, Auburn, AL, U.S.A.

Back, M. A., Haydock, P. P. J., and Jenkinson, P. 2002. Disease complexes involving plant parasitic nematodes and soilborne pathogens. Plant Pathol. 51:683-697.

Belder, P., Bouman, B. A. M., Cabangon, R., Lu, G., Quilang, E. J. P., Li, Y. H., Spiertz, J. H. J., and Tuong, T. P. 2004. Effect of water-saving irrigation on rice yield and water use in typical lowland conditions in Asia. Agric. Water Manage. 65:193-210.

Bowman, P., and Bloom, J. R. 1966. Breaking the resistance of tomato varieties to Fusarium wilt by Meloidogyne incognita. Phytopathology 56:871.

Bridge, J., Plowright, R. A., and Peng, D. 2005. Nematode parasites of rice. Pages 87-130 in: Plant Parasitic Nematodes in Subtropical and Tropical Agriculture. M. Luc, R. A. Sikora, and J. Bridge, eds. CABI Publishing, Wallingford, U.K.

Cao, J., Yang, C., Li, L., Jiang, L., Wu, Y., Wu, C., Bu, Q., Xia, G., Liu, X., Luo, Y., and Liu, J. 2016. Rice plasma membrane protomics reveals Manaporthe oryzae promoters susceptibility by sequential activation of host hormone signaling pathways. Mol. Plant Microbe Interact. 29: 902-913.
De Vleesschauwer, D., Xu, J., and Höfte, M. 2014. Making sense of hormone-mediated defense networking: From rice to Arabidopsis. Front. Plant Sci. 5:611.

De Waele, D., and Elsen, A. 2007. Challenges in tropical plant nematology. Ann. Rev. Phytopathol. 45:457-485.

Ding, X. H., Cao, Y. L., Huang, L. L., Zhao, J., Xu, C. G., Li, X. H., and Wang, S. P. 2008. Activation of the indole-3-acetic acid-amido synthetase GH3-8 suppresses expansin expression and promotes salicylate- and jasmonateindependent basal immunity in rice. Plant Cell 20:228-240.

Domingo, C., Andres, F., Tharreau, D., Iglesias, D. J., and Talon, M. 2009. Constitutive expression of OsGH3.1 reduces auxin content and enhances defense response and resistance to a fungal pathogen in rice. Mol. Plant Microbe Interact. 22:201-210.

Du, Z., Zhou, X., Ling, Y., Zhang, Z. H., and Su, Z. 2010. agriGO: A GO analysis toolkit for the agricultural community. Nucleic Acids Res. 38: W64-W70.

FAOSTAT. 2013 FAOSTAT database. Food and Agriculture Organization of the United Nations, Rome. http://faostat3.fao.org

Frei, M., Wissuwa, M., Pariasca-Tanaka, J., Chen, C. P., Sudekum, K. H., and Kohno, Y. 2012. Leaf ascorbic acid level-Is it really important for ozone tolerance in rice? Plant Physiol. Biochem. 59:63-70.

Fu, J., and Wang, S. P. 2011. Insights into auxin signaling in plant-pathogen interactions. Front. Plant Sci. 2:74.

Hamamouch, N., Li, C. Y., Seo, P. J., Park, C. M., and Davis, E. L. 2011 Expression of Arabidopsis pathogenesis-related genes during nematode infection. Mol. Plant Pathol. 12:355-364.

Hardcastle, T. J., and Kelly, K. A. 2010. baySeq: Empirical Bayesian methods for identifying differential expression in sequence count data BMC Bioinformatics 11:422

Hodges, D. M., DeLong, J. M., Forney, C. F., and Prange, R. K. 1999. Improving the thiobarbituric acid-reactive-substances assay for estimating lipid peroxidation in plant tissues containing anthocyanin and other interfering compounds. Planta 207:604-611.

Hofmann, J., El Ashry, A., Anwar, S., Erban, A., Kopka, J., and Grundler, F. 2010. Metabolic profiling reveals local and systemic responses of host plants to nematode parasitism. Plant J. 62:1058-1071.

Höller, S., Meyer, A., and Frei, M. 2014. Zinc deficiency differentially affects redox homeostasis of rice genotypes contrasting in ascorbate level. J. Plant Physiol. 171:1748-1756.

Ji, H. L., Gheysen, G., Denil, S., Lindsey, K., Topping, J. F., Nahar, K., Haegeman, A., De Vos, W. H., Trooskens, G., Van Criekinge, W., De Meyer, T., and Kyndt, T. 2013. Transcriptional analysis through RNA sequencing of giant cells induced by Meloidogyne graminicola in rice roots. J. Exp. Bot. 64:3885-3898.

Kim, S. Y., and Volsky, D. J. 2005. PAGE: Parametric analysis of gene set enrichment. BMC Bioinformatics 6:144.

Koga, H., Dohi, K., and Mori, M. 2004. Abscisic acid and low temperatures suppress the whole plant-specific resistance reaction of rice plants to the infection of Magnaporthe grisea. Physiol. Mol. Plant Pathol. 65:3-9.

Kreye, C., Bouman, B. A. M., Reversat, G., Fernandez, L., Cruz, C. V., Elazegui, F., Faronilo, J. E., and Llorca, L. 2009. Biotic and abiotic causes of yield failure in tropical aerobic rice. Field Crops Res. 112: 97-106.

Kyndt, T., Denil, S., Bauters, L., Van Criekinge, W., and De Meyer, T. 2014. Systemic suppression of the shoot metabolism upon rice root nematode infection. PLoS One 9:e106858.

Kyndt, T., Denil, S., Haegeman, A., Trooskens, G., Bauters, L., Van Criekinge, W., De Meyer, T., and Gheysen, G. 2012a. Transcriptional reprogramming by root knot and migratory nematode infection in rice. New Phytol. 196:887-900.

Kyndt, T., Nahar, K., Haegeman, A., De Vleesschauwer, D., Hofte, M., and Gheysen, G. 2012b. Comparing systemic defence-related gene expression changes upon migratory and sedentary nematode attack in rice. Plant Biol. 14:73-82.

Li, D., Wang, L., Wang, M., Xu, Y. Y., Luo, W., Liu, Y. J., Xu, Z. H., Li, J., and Chong, K. 2009. Engineering OsBAK1 gene as a molecular too to improve rice architecture for high yield. Plant Biotechnol. J. 7: 791-806.

Mantelin, S., Bellafiore, S., and Kyndt, T. 2017. Meloidogyne graminicola: A major threat to rice agriculture. Mol. Plant Pathol. 18:3-15.

Mei, C. S., Qi, M., Sheng, G. Y., and Yang, Y. N. 2006. Inducible overexpression of a rice allene oxide synthase gene increases the endogenous jasmonic acid level, $P R$ gene expression, and host resistance to fungal infection. Mol. Plant Microbe Interact. 19:1127-1137.

Nahar, K., Kyndt, T., De Vleesschauwer, D., Hofte, M., and Gheysen, G. 2011. The jasmonate pathway is a key player in systemically induced defense against root knot nematodes in rice. Plant Physiol. 157: 305-316. 
Nahar, K., Kyndt, T., Nzogela, Y. B., and Gheysen, G. 2012. Abscisic acid interacts antagonistically with classical defense pathways in ricemigratory nematode interaction. New Phytol. 196:901-913.

Nicol, J. M., Turner, S. J., Coyne, D. L., den Nijs, L., Hockland, S., and Tahna Maafi, Z. 2011. Current nematode threats to world agriculture. Pages 21-43 in: Genomics and molecular genetics of plant-nematode interactions. J. T. Jones, G. Gheysen, and C. Fenoll, eds. Springer, London.

Park, H., Ryu, H., Kim, B., Kim, S., Yoon, I., and Nam, K. 2011. A subset of OsSERK genes, including OsBAK1, affects normal growth and leaf development of rice. Mol. Cells 32:561-569.

Prabhu, A.S., Filippi, M.C., Silva, G.B., Lobo, V.L.S., and Morais, O.P. 2009. An Unprecedented Outbreak of Rice Blast on a Newly Released Cultivar BRS Colosso in Brazil. Pages 257-266 in: Advances in Genetics, Genomics and Control of Rice Blast Disease. Springer, Dordrecht, The Netherlands.

Prasad, R. 2011. Aerobic rice systems. Adv. Agron. 111:207-247.

Qi, M., and Yang, Y. N. 2002. Quantification of Magnaporthe grisea during infection of rice plants using real-time polymerase chain reaction and northern blot/phosphoimaging analyses. Phytopathology 92:870-876.

Reversat, G., Boyer, J., Sannier, C., and Pando-Bahuon, A. 1999. Use of a mixture of sand and water-absorbent synthetic polymer as substrate for the xenic culturing of plant-parasitic nematodes in the laboratory. Nematology 1:209-212.

Robinson, M. D., and Oshlack, A. 2010. A scaling normalization method for differential expression analysis of RNA-seq data. Genome Biol. 11:R25.

Rich, J. R., Brito, J. A., Kaur, R., and Ferrell, J. A. 2009. Weed species as hosts of Meloidogyne: A review. Nematropica 39:157-185.

Riemann, M., Haga, K., Shimizu, T., Okada, K., Ando, S., Mochizuki, S., Nishizawa, Y., Yamanouchi, U., Nick, P., Yano, M., Minami, E., Takano, M., Yamane, H., and Iino, M. 2013. Identification of rice allene oxide cyclase mutants and the function of jasmonate for defence against Magnaporthe oryzae. Plant J. 74:226-238.

Sasser, J. N., and Freckman, D. W. 1987. A world perspective on nematology: The role of the society. Pages 7-14 in: Vistas on Nematology. J. A. Veech, and D. W. Dickson, eds. Society of Nematologists Inc., Hyattsville, MD, U.S.A.

Seck, P. A., Diagne, A., Mohanty, S., and Wopereis, M. C. S. 2012. Crops that feed the world 7: Rice. Food Secur. 4:7-24.

Shimizu, T., Miyamoto, K., Minami, E., Nishizawa, Y., Iino, M., Nojiri, H., Yamane, H., and Okada, K. 2013. OsJAR1 contributes mainly to biosynthesis of the stress-induced jasmonoyl-isoleucine involved in defense responses in rice. Biosci. Biotechnol. Biochem. 77:1556-1564.

Shimono, M., Sugano, S., Nakayama, A., Jiang, C. J., Ono, K., Toki, S., and Takatsuji, H. 2007. Rice WRKY45 plays a crucial role in benzothiadiazoleinducible blast resistance. Plant Cell 19:2064-2076.

Sidhu, G., and Webster, J. M. 1977. Predisposition of tomato to wilt fungus (Fusarium oxysporum lycopersici) by root-knot nematode (Meloidogyne incognita). Nematologica 23:436-442.

Silverman, P., Seskar, M., Kanter, D., Schweizer, P., Metraux, J. P., and Raskin, I. 1995. Salicylic acid in rice-Biosynthesis, conjugation, and possible role. Plant Physiol. 108:633-639.
Skamnioti, P., and Gurr, S. J. 2009. Against the grain: Safeguarding rice from rice blast disease. Trends Biotechnol. 27:141-150.

Spence, C. A., Lakshmanan, V., Donofrio, N., and Bais, H. P. 2015. Crucial roles of abscisic acid biogenesis in virulence of rice blast fungus Magnaporthe oryzae. Front. Plant Sci. 6:1.

Talbot, N. J. 2003. On the trail of a cereal killer: Exploring the biology of Magnaporthe grisea. Annu. Rev. Microbiol. 57:177-202.

Taniguchi, S., Hosokawa-Shinonaga, Y., Tamaoki, D., Yamada, S., Akimitsu, K., and Gomi, K. 2014. Jasmonate induction of the monoterpene linalool confers resistance to rice bacterial blight and its biosynthesis is regulated by JAZ protein in rice. Plant Cell Environ. 37:451-461.

Thimm, O., Blasing, O., Gibon, Y., Nagel, A., Meyer, S., Kruger, P., Selbig, J., Muller, L. A., Rhee, S. Y., and Stitt, M. 2004. MAPMAN: A userdriven tool to display genomics data sets onto diagrams of metabolic pathways and other biological processes. Plant J. 37:914-939.

Thuan, N. T. N., Bigirimana, J., Roumen, E., Van Der Straeten, D., and Höfte, M. 2006. Molecular and pathotype analysis of the rice blast fungus in North Vietnam. Eur. J. Plant Pathol. 114:381-396.

Trapnell, C., Pachter, L., and Salzberg, S. L. 2009. TopHat: Discovering splice junctions with RNA-Seq. Bioinformatics 25:1105-1111.

Trapnell, C., Williams, B. A., Pertea, G., Mortazavi, A., Kwan, G., van Baren, M. J., Salzberg, S. L., Wold, B. J., and Pachter, L. 2010. Transcript assembly and quantification by RNA-Seq reveals unannotated transcripts and isoform switching during cell differentiation. Nat. Biotechnol. 28:511-515

Velikova, V., Yordanov, I., and Edreva, A. 2000. Oxidative stress and some antioxidant systems in acid rain-treated bean plants-Protective role of exogenous polyamines. Plant Sci. 151:59-66.

Wondafrash, M., Van Dam, N. M., and Tytgat, T. O. G. 2013. Plant systemic induced responses mediate interactions between root parasitic nematodes and aboveground herbivorous insects. Front. Plant Sci. 4:87.

Yamada, S., Kano, A., Tamaoki, D., Miyamoto, A., Shishido, H., Miyoshi, S., Taniguchi, S., Akimitsu, K., and Gomi, K. 2012. Involvement of OsJAZ8 in jasmonate-induced resistance to bacterial blight in rice. Plant Cell Physiol. 53:2060-2072.

Yang, D. L., Yang, Y. N., and He, Z. H. 2013. Roles of plant hormones and their interplay in rice immunity. Mol. Plant 6:675-685.

Yang, Y. N., Qi, M., and Mei, C. S. 2004. Endogenous salicylic acid protects rice plants from oxidative damage caused by aging as well as biotic and abiotic stress. Plant J. 40:909-919.

Zeigler, R.S., Tohme, J., Nelson, R., Levy, M., and Correavictoria, F.J. 1994. Lineage exclusion-A proposal for linking blast population analysis to resistance breeding. Pages. 267-292 in: Rice Blast Disease. R. S. Zeigler, P. S. Teng, and S. A. Leong, eds. Commonwealth Agricultural Bureaux, Wallingford, U.K.

\section{AUTHOR-RECOMMENDED INTERNET RESOURCE}

Gene Expression Omnibus repository, GSE89449 page: https://www.ncbi.nlm. nih.gov/geo/query/acc.cgi?token=qxalwueyzlqbnor\&acc=GSE89449 